T.Yu. Gogberashvilii ${ }^{1,2}$, Yu.V. Mikadze ${ }^{1}$

${ }^{1}$ Pirogov Russian National Medical Research University, Moscow, Russian Federation

${ }^{2}$ Scientific Center of Children’s Health, Moscow, Russian Federation

\title{
Dynamics of higher mental function changes in children and adolescents with partial forms of epilepsy in clinical remission
} Author affiliation:

Gogberashvili Tinatin Yuzovna, MD, associate professor at Pirogov Russian National Medical Research University of the Ministry of Health of Russia.

Address: 1, Ostrovityanova Str., Moscow, 117997, tel.: +7 (495) 434-83-13, e-mail: tinatina2004@mail.ru Article received: 22.03.2013, accepted for publication: 14.05.2013.

Study aim: to study the dynamics of changes of higher mental functions in children and adolescents with partial epilepsy forms. Study participants and methods. The study involved patients 6-16 years of age (15 people). Complex neuropsychological examination of the higher mental functions was conducted in children and adolescents with localized (focal, partial) epilepsy forms. Repeated neuropsychological examination was conducted 1 year later to reveal changes in the preregistered symptoms. Results. The most frequent and pronounced disorders in the primary examination were spatial, kinesthetic and constructive praxis disorders, visual-spatial and acoustic-nonvoice gnosis disorders, increased inhibition of traces, audio-verbal and visual memory constriction, defective order of reproducing words (figures) in stimulus sequence (transient errors), spatial errors in visual-constructive thinking, paragraphia. Thus, higher intensity of symptoms of the functional cerebral block II was registered. Repeated examination 1 year later showed slight changes in symptoms characterizing cerebral block II disorders; more serious changes affected symptoms connected with disorders in cerebral blocks III and I. Conclusions: symptom complexes of the functional block II, directly connected to epileptic nidi, appeared to be more resistant and hardly amenable to involution.

Keywords: partial (focal) epilepsy, neuropsychological examination, higher mental functions, childhood and adolescence.

(Pediatric pharmacology. 2013; 10 (3): 56-61)

\section{INTRODUCTION}

In pediatric neurology, pediatric and adolescent epilepsy is one of the main pathology form defined as “.... a chronic encephalopathy characterized by reiterative non-provoked seizures of movement, sensitive, vegetative, cognitive or mental malfunctioning due to excessive 
neuronal discharges” [1]. Epilepsy morbidity involves $0.5-0.75 \%$ of children and has a tendency to grow.

Along with paroxysmal manifestations, mental disorders peculiar to epilepsy play an important role in its clinical presentation [2, 3]. The study of mental alteration in children and adults at epilepsy opened a new stage of exploring the correlation between the disease and cognitive malfunction. W. Lennox (1942) and W. Penfield (1950) were among the first researchers in this area. Modern scientists continue studying cognitive malfunction in patients with epilepsy (V.A. Karlov, 1992; E.L. Wasserman, 1997; A.I. Boldyrev, 1998; S.V. Balkanskaya, 2000; A.S. Petrukhin, 2000; K.V. Voronkova, 2002; L.R. Zenkov, 2007; L.A. Troitskaya, 2007, etc.).

It has been revealed that the condition of cognitive functions in children with epilepsy depends on numerous clinical and social factors, such as the disease etiology, condition of cerebral organic structure, paroxysmal syndrome’s dynamics, cerebral epileptic activity, reaction to treatment, degree of sociopedagogical adaptation and acknowledgment of their condition by patients. It is well known that the patient's pessimism favors formation of passiveness and depression, which negatively influence the disease prognosis. An important factor is the awareness of their disease of patients and their family and friends [4-8]. According to the literary data, mental development regress is considerably more often observed in children with active epilepsy; however, the degree and type of central nervous system's affection at the moment of disease manifestation affect the conclusive prognosis. In case onset of epilepsy takes place in infancy, the prognosis is less favorable. This is associated both with immaturity of defense mechanisms and inhibitory action that the pathological process has on the child's mental development. Intense cognitive disorders cause incapacitation of children with epilepsy [9-11].

According to a range of studies, pathological process at partial epilepsy forms involves not only the focal zones, but also other cerebral regions, which are not connected with the pathological focus [9, 12]. Complex presentation of disturbed higher mental functions (HMF) at epilepsy determines the urgency of a neuropsychological study aimed at exploring the influence that the disease has both on the current state of HMF and on the prospects of further mental development.

We conducted an examination of a large sample of children $(n=82)$ with partial frontal, temporal, parietooccipital and occipital epilepsy forms, which showed that the disorders that appear at epilepsy are characterized by a complex set of symptoms peculiar to more than just a neuropsychological syndrome [13]. Different types of partial epilepsies lead to a whole 
range of symptom complexes, among which we can distinguish between the syndrome associated with the epileptic focus and concurrent extrafocal syndromes.

2 main variants of meta-syndrome (logical combination of neuropsychological syndromes) have been distinguished and described regardless of the focus's location and the age of children [13]. These variants differ in the degree of intensity of the syndrome associated with the epileptic focus and of the other revealed syndromes.

The first variant defined as the specific variant of meta-syndrome includes the main (the most intense) syndrome associated with the epileptic focus and a range of other, less intense syndromes and is characterized by a complex presentation of a combination of concurrent syndromes of different cerebral regions, which are not associated with the epileptic focus.

The second, non-specific variant of meta-syndrome does not have the main syndrome; all the involved syndromes or most of them had approximately the same degree of intensity. The syndrome characterizing the epileptic focal zone's affection does not stand out, i.e. the pathological process almost equally involves different cerebral regions.

The study also revealed that certain combinations of syndromes, which depend on the focus's localization, disease manifestation time, seizure types and disease etiology form within both specific and non-specific meta-syndromes [14].

Age dynamics of cognitive disorders is the important aspect of mental functions' development prognosis in children with epilepsies. It is especially true for cases with the remission of epileptic seizures, where the control of seizures prevents their negative influence on the quality of life and emphasizes the non-paroxysmal component of the disease - cognitive functions and emotional-personality characteristics. The issue of HMF state dynamics in children with epilepsy is insufficiently covered in the current neuropsychology.

The earlier studies showed that the initial presentation of cognitive disorders may range from coarsely manifested HMF disorders to defect's partiality depending on the epileptic focus's localization and the epilepsy form. According to some literary data, it is not possible to achieve complete recovery of cognitive functions even in case of stable remission [15-18]. The authors note a certain equalization of intellectual-mnestic processes after the termination of seizures in case of a correctly selected therapy and purposeful correctional work. The study of K.V. Voronkova (2007) revealed that the electroencephalographic presentation changes and the epileptiform activity focus migration is observed with age in children with symptomatic epilepsy forms. Migration is extrafrontal, usually into the pretemporal area, at partial frontal epilepsy, and from pretemporal to posttemporal at partial temporal epilepsy. HMF disorders usually remain intact in these children, even in the disease's clinical remission 
period; dysfunction of parietal and temporal cerebral regions are more often revealed at that [19].

Irregular maturation of a child's brain in the process of ontogenesis, which follows the heterochrony law, is accompanied by the complication of levels of cerebral functional organization and child's cognitive development and takes a certain chronological course. The study of specificity of dynamics of cognitive sphere formation regularities and of HMF genesis in the setting of diffuse cerebral pathology, particularly at epilepsy, is highly important for determining prospects of child's further mental development and conducting the adequate correctional work [20].

Study aim is to appraise the dynamics of HMF state in children with partial temporal, parietooccipital and occipital epilepsy forms in the setting of the shortly achieved remission.

\section{PATIENTS AND METHODS}

\section{Study participants}

The study was conducted on the basis of the Moscow Russian children's clinical hospital (neuropsychiatry unit \#1).

The study involved children and adolescents of 6-16 years of age with partial focal epilepsy forms ( $n=15)$, who were admitted to the unit for the control examination. The clinical group involved children with symptomatic epilepsy with simple partial and partial seizures with secondary generalization. The disease manifestation age varied from 3 to 6 years.

The division of children by epilepsy forms is given in tb. 1 .

Clinical remission by the moment of study was 6-8 months.

Table 1. Spread of children by epilepsy forms

\begin{tabular}{|l|c|}
\hline \multicolumn{1}{|c|}{ Epilepsy form } & Number of children \\
\hline Partial temporal & 9 \\
\hline Partial parietooccipital & 4 \\
\hline Partial occipital & 2 \\
\hline
\end{tabular}

\section{Study methods}

All children received a standard complex of control clinical-instrumental medical examination during their hospital stay. All participants were regularly treated with various anticonvulsants, which remained the same throughout the study. There have been no specialized psychological or pedagogical correctional exercises for the participants throughout the observation period; the patients have not received specialized treatment with nootropics - exclusion of this factor 
is important for an unambiguous interpretation of causes of the possible dynamic changes. Intellectual condition of the study participants allowed them to understand and perform tests involved in the general neuropsychological examination.

There were 2 neuropsychological HMF examinations - the initial and the repeated (1 year later). Our methodology was based on the set of general neuropsychological study techniques developed by A.R. Luria and his followers. General neuropsychological examination includes a conversation, examination of movement functions, perception, language functions, memory and intellect.

According to the conception of 3 functional cerebral blocks (A.R. Luria), all of them take a specific part in actualizing mental functions. As neuropsychological alterations at epilepsy and many other diseases do not have a well-defined local character in whole, despite focal forms of disease, we not only correlated the observed alterations with particular cerebral regions, but also appraised them from the point of view of work of each functional block, its participation in the brain's integrative work in whole.

We conducted a qualitative analysis of symptoms (description of a structure of the emergent cognitive deficiencies by correlating them with 3 functional blocks) and a quantitative analysis of degree of their intensity (numerical score of the revealed symptoms) in children and adolescents with partial epilepsy forms in order to reveal HMF change dynamics.

We used a numerical score system generally adopted in the national neuropsychology [21] for quantitative data analysis: 0 corresponded to the lack of disorders, 1 - to the rate of mistakes up to $30 \%$ (mild disorders and a possibility of unassisted correction of mistakes), 2 - to the $30-70 \%$ rate of mistakes (moderate defect's intensity, a possibility of correction and task fulfillment in case the observer gives hints), 3 - to the $70-100 \%$ rate of mistakes (in case of a manifested defect). We calculated the average scores of the revealed symptoms for each functional cerebral block in order to determine the degree of disorder's intensity.

\section{Statistical data manipulation}

Statistical significance of differences in results associated with all cerebral blocks in children examined in dynamics was determined using the Wilcoxon t-criterion (it is used to compare parameters obtained in 2 different conditions in the same sample; it is often used in psychological studies) [22].

\section{RESULTS AND DISCUSSION}

According to the primary neuropsychological examination of 15 children with partial temporal, parietooccipital and occipital epilepsy forms, the most intense (pic. 1) were the 
neuropsychological symptoms associated with the II functional cerebral block's dysfunction (block of information reception, storage and organization).

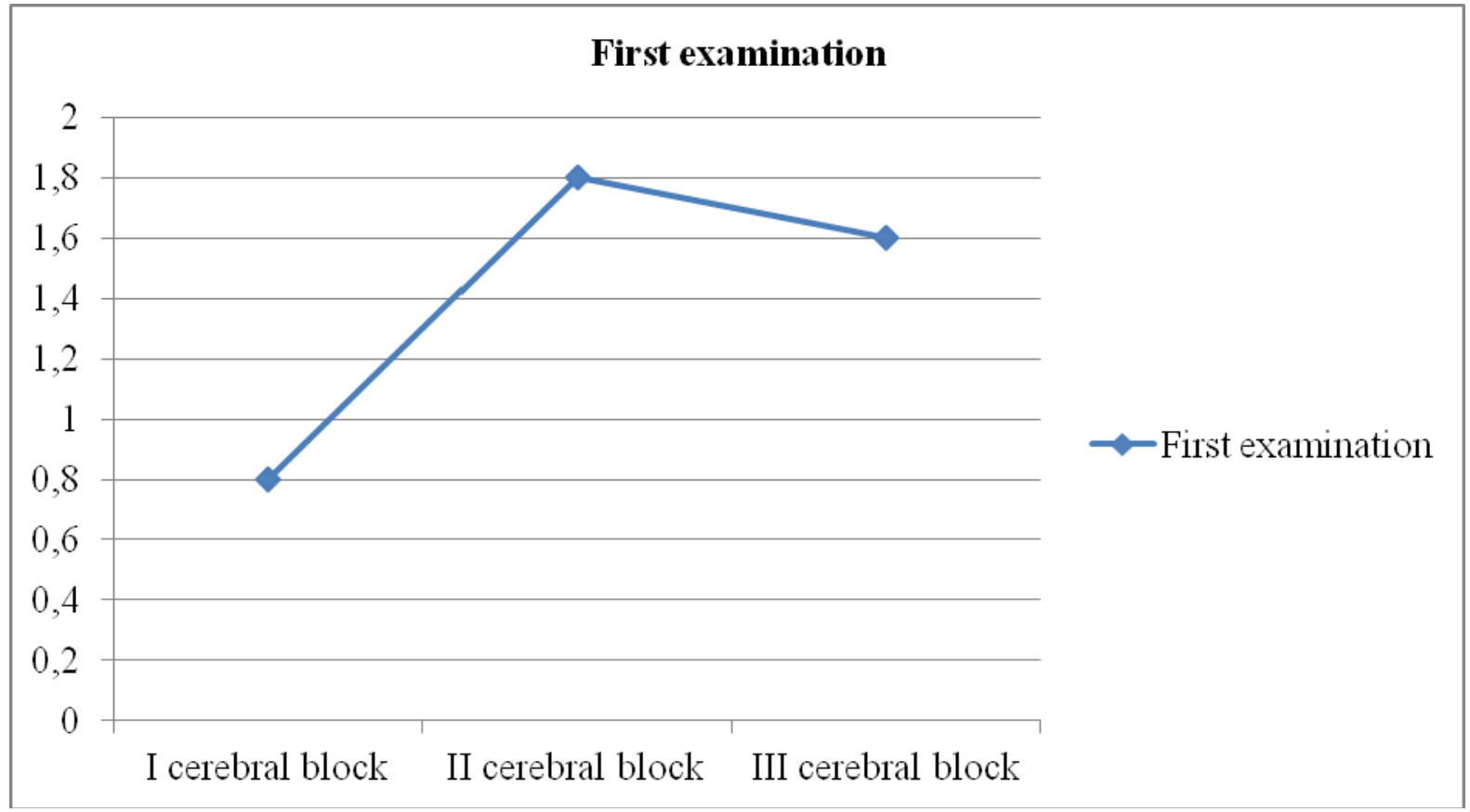

Pic. 1. Initial intensity of neuropsychological symptoms of different functional cerebral blocks (Y-axis - average scores, X-axis - cerebral blocks), average parameters ( $\mathrm{n}=15)$

According to the primary neuropsychological examination of children, the most frequent and intense were the following symptoms: disturbed spatial, kinetic and constructive praxis, visual-spatial and acoustic nonvoice gnosis, increased inhibition of traces, audio-verbal and visual memory constriction, defective order of reproducing words (figures) in a stimulus sequence (transient errors), spatial errors in visual-constructive thinking and paragraphia.

Symptoms associated with the malfunction of the III (block of programming, regulation and control) and the I (energy) functional cerebral blocks were less manifested. The most intense among them were the following symptoms: disturbed voluntary attention and reference base of activity, perseveration in visual memory, defective order of reproducing words in a stimulus sequence (rigid errors), increased fatigability and attention fluctuation.

Higher manifestation of the II functional block's symptoms was caused by the location of the epileptic focus in paleoencephalon (temporal, parietooccipital and occipital partial epilepsy forms) in the examined children, exactly where the II functional block' structures are situated. It is well known that at partial epilepsy pathological influence spreads outside of the focus, in the first place into the cerebral structures adjacent to the focus [23-25]. Cerebral cortex of the 
posterior regions has a range of common peculiarities, which allows uniting it into one cerebral block (II functional block), where zones are hierarchically organized on the common principle, are highly modally specific and are unite to accomplish the common task reception, storage and organization of information. Naturally, pathological process spreads from a temporal, occipital or parietal focus to the adjacent regions of the posterior cerebrum united into the II functional block.

In whole, we distinguished specific variants of meta-syndromes (logical combination of neuropsychological symptom complexes and neuropsychological syndromes associated with different cerebral regions), where the most intense are the neuropsychological symptoms associated directly with the epileptic focal zone, while extrafocal symptoms (neuropsychological symptoms, which are not associated with the epileptic focal zone) are less manifested. We reached the similar conclusions about the meta-syndromic character of disturbed HMF at partial epilepsy in children in the previous study, which involved a large sample of patients [14].

After the repeated neuropsychological examination of these children 1 year later, we compared results of the 2 examinations by comparing average values of symptoms specific to the affection of the I, II and III cerebral blocks (pic. 2-4).

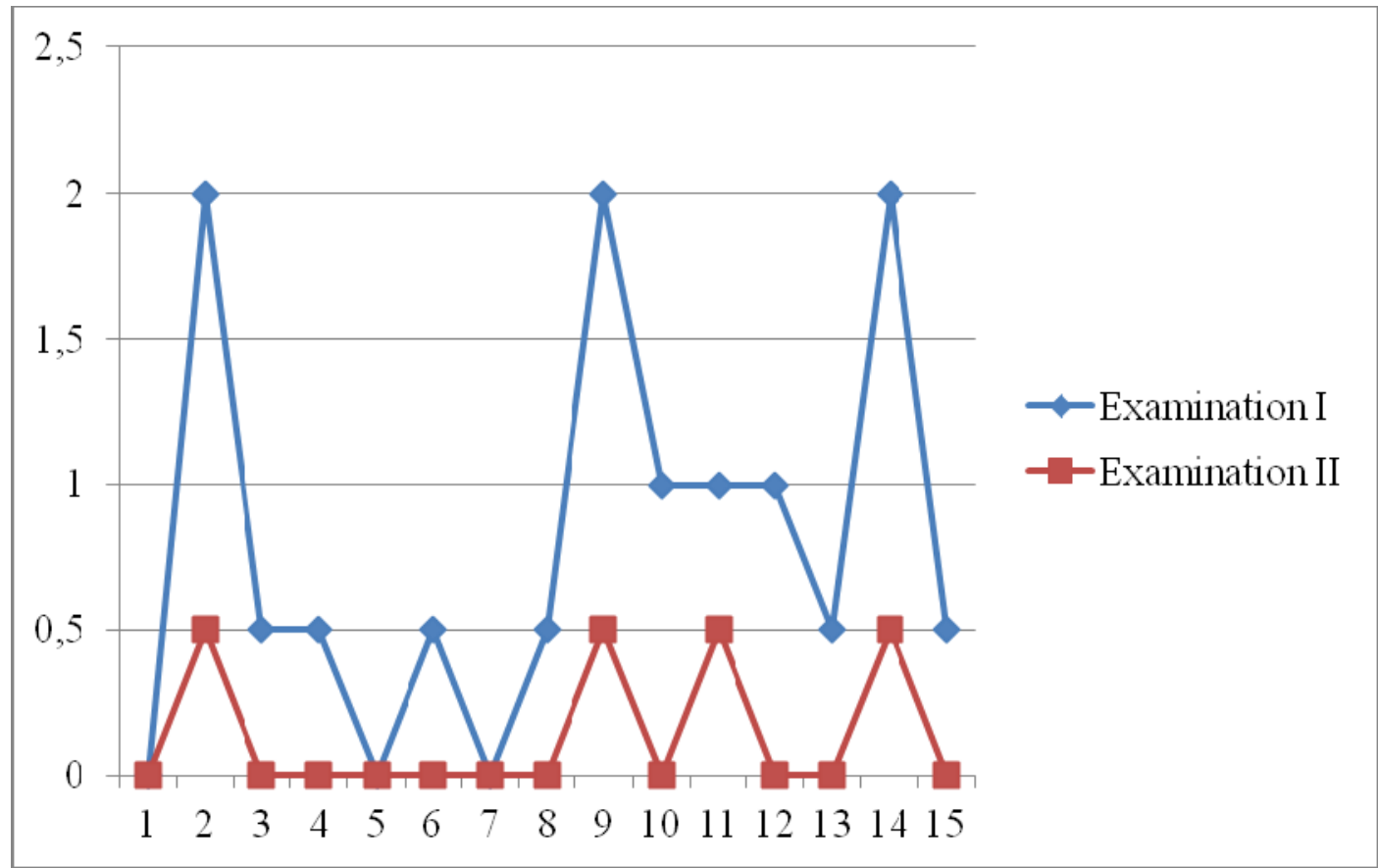

Pic. 2. Dynamics of manifestation of neuropsychological symptoms of the I functional block (Y-axis - average scores, $\mathrm{X}$-axis - patients) 


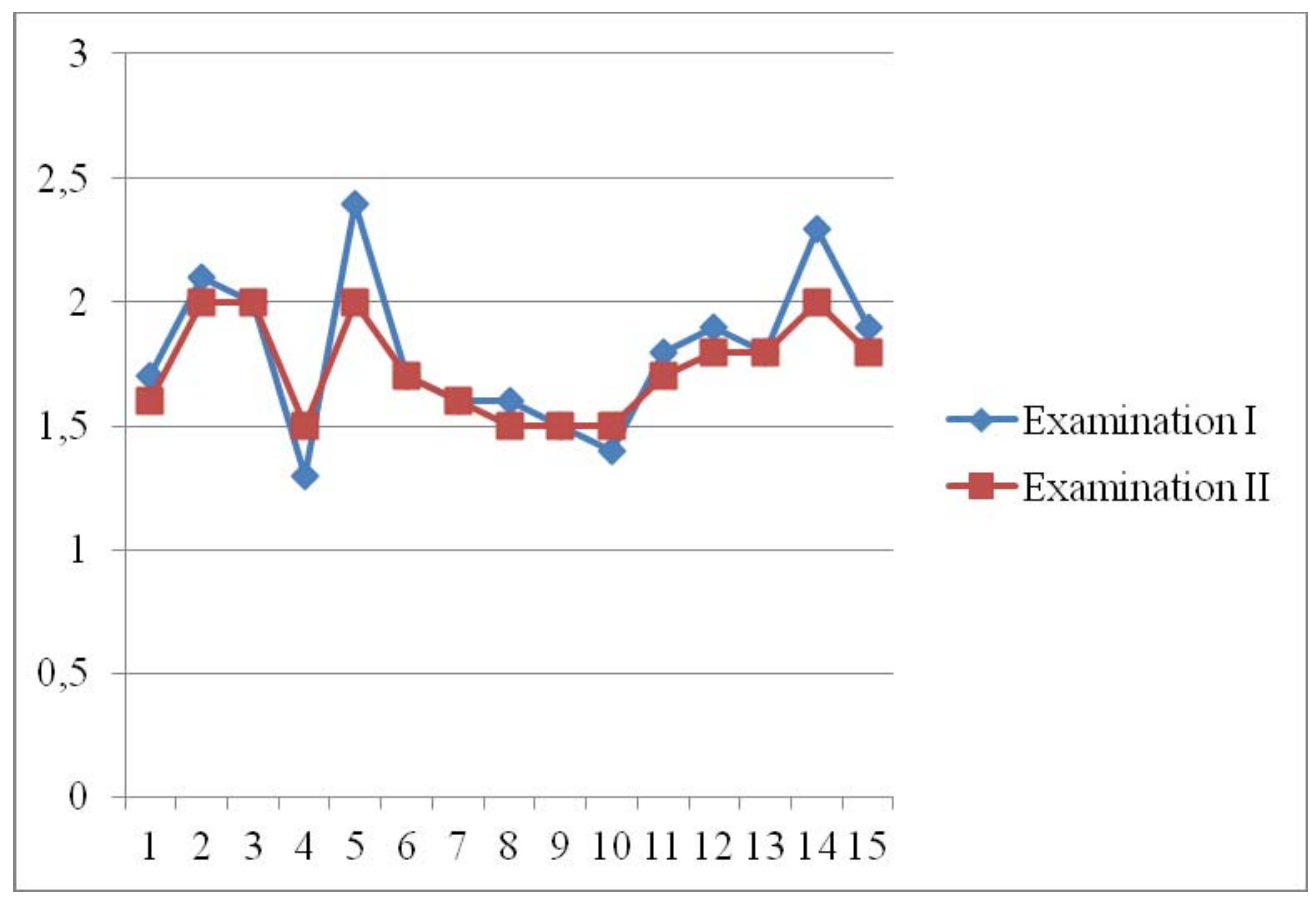

Pic. 3. Dynamics of manifestation of neuropsychological symptoms of the II functional block (Y-axis - average scores, $\mathrm{X}$-axis - patients)

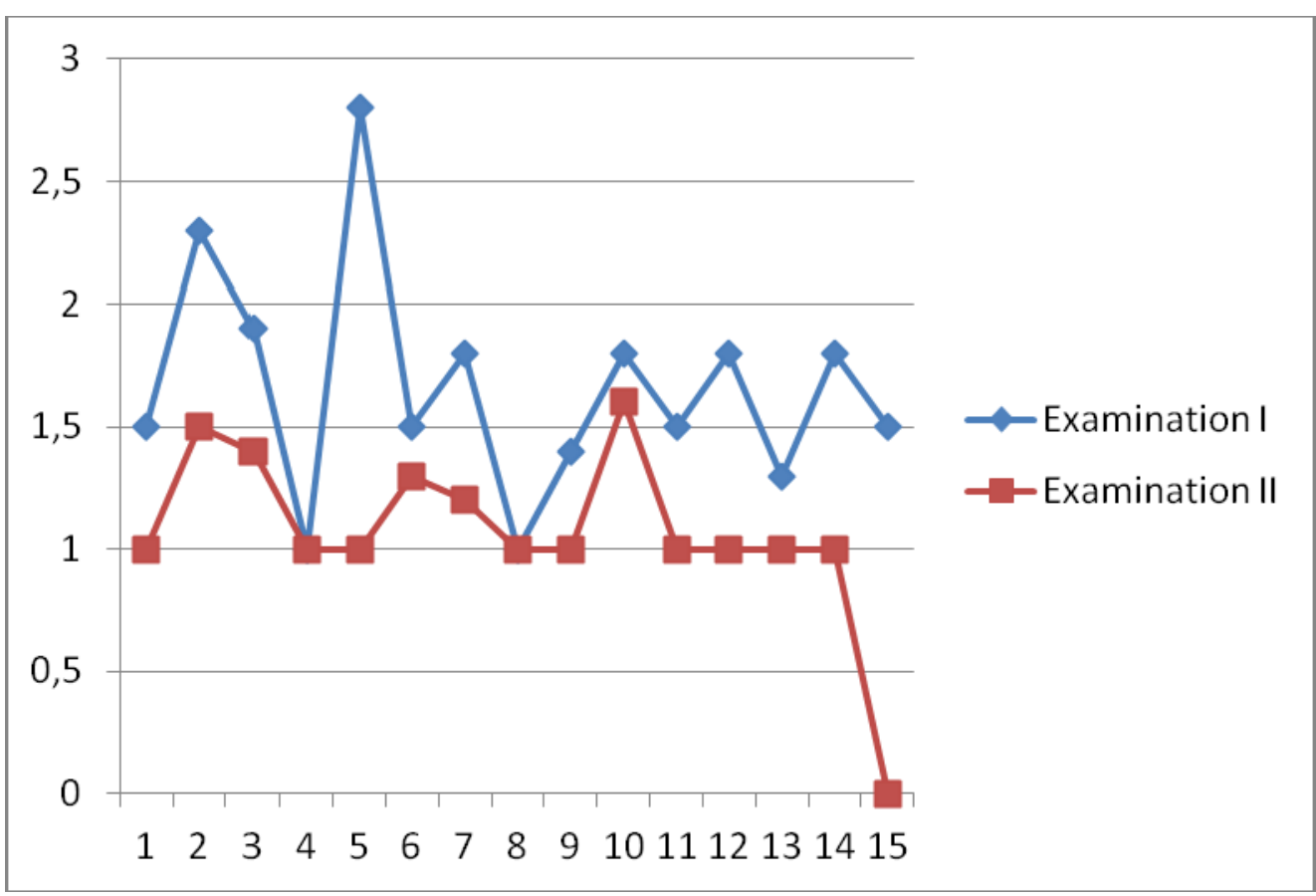

Pic. 4. Dynamics of manifestation of neuropsychological symptoms of the III functional block (Y-axis - average scores, $\mathrm{X}$-axis - patients)

As we can see from the given data, the repeated examination 1 year later revealed clear positive dynamics in at least $1 \mathrm{HMF}$ functional block in all 1t patients, in 2 blocks out of 3 in 12 patients. The comparative analysis of average scores (pic. 5) revealed that the positive 
dynamics in the I functional block's symptoms was 87.5\%, in the III block's symptoms 37.5\%. Given that the children were not receiving special correctional help and nootropic therapy, we may conclude that positive HMF dynamics was caused mainly by the drug suppression of epileptic cerebral process; it manifested itself clinically in the remission of seizures. Thus, the obtained data indicate that cerebral epileptization causes cognitive activity disorder in children regardless of the organic background. We may also assume that additional therapeutic measures in the form nootropic support and special correction may provide for an even more significant positive HMF dynamics in children with remission of epileptic seizures.

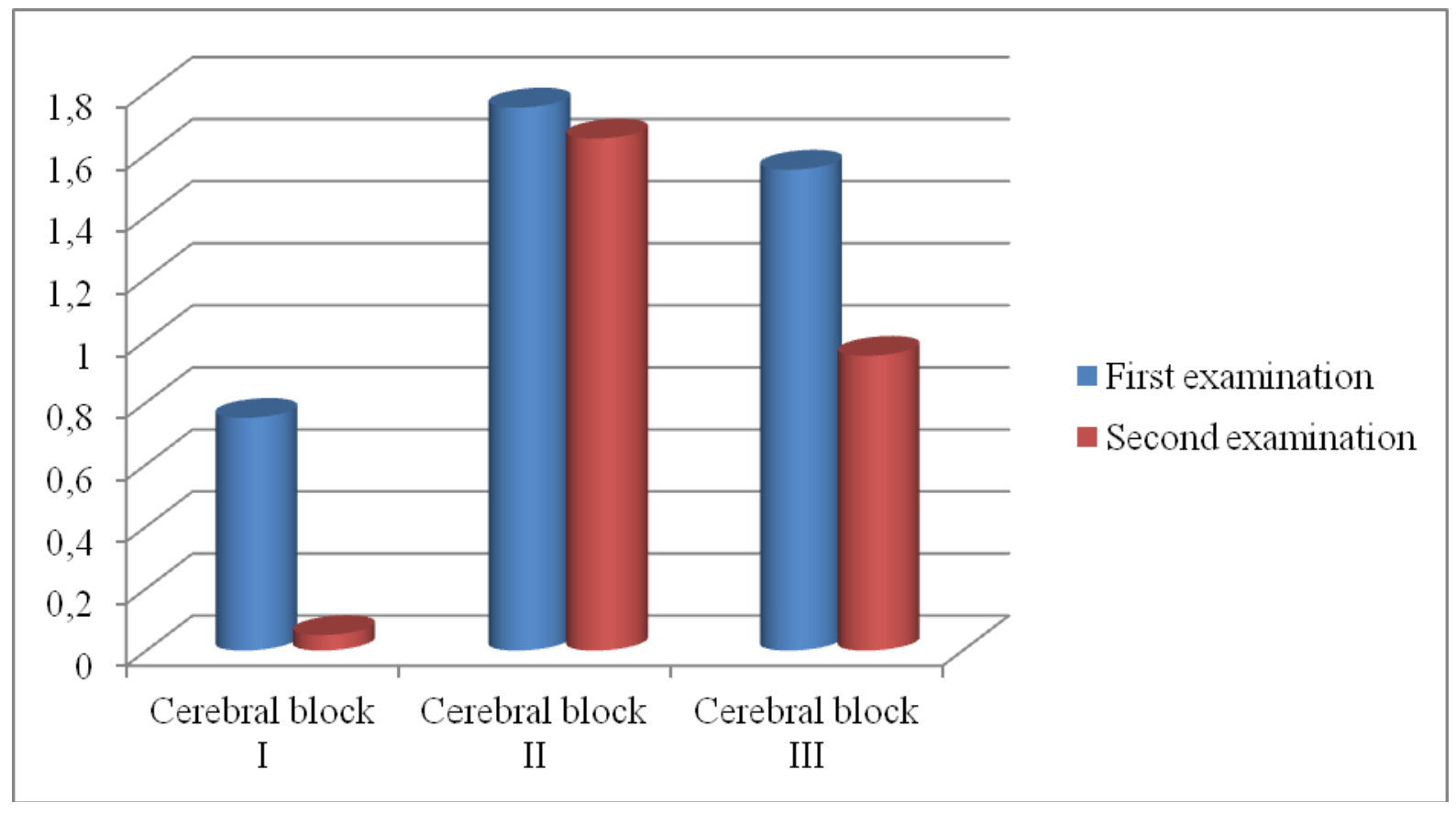

Pic. 5. Dynamics of average manifestation of neuropsychological symptoms of different functional cerebral blocks (Y-axis - average scores, X-axis - cerebral blocks)

Differences in the I and III functional cerebral blocks' pairs are significant $(p<0.01)$; the difference in the II block does not reach the level of statistical significance ( $p>0.05$ ).

Analysis of data showed that the minimally manifested dynamics of HMF alterations was observed in symptoms defining the II cerebral block's malfunctioning; the higher manifestation was observed in symptoms associated with the III and the I cerebral blocks' malfunctioning.

Differences in the manifestation of positive dynamics are caused by the location of the epileptic focus, as has already been stated above, in the II functional cerebral block's 
structures (temporal, parietooccipital and occipital partial epilepsy forms). Thus, symptom complexes of the II functional block, directly associated with the epileptic foci, appeared to be stabler and are almost irreversible.

A more detailed analysis revealed "irregularity" of dynamics in separate symptoms within cerebral blocks.

Positive dynamics was observed in such symptoms of the III, II and I cerebral blocks as disturbed voluntary attention and reference base of activity, perseveration in visual memory, defective order of reproducing words in a stimulus sequence (rigid errors), disturbed postural, constructive and dynamic praxis, visual-spatial gnosis, difficulty in preserving spatial characteristics of a stimulus, increased inhibition of traces in visual memory, paragraphia, increased fatigability and attention fluctuation. These symptoms are associated with functions of pre- and postfrontal, parietooccipital and partially deep cerebral regions.

Negative or no dynamics was observed (average penalty scores remain the same or rise) in the average scores of such symptoms as disturbed spatial praxis and acoustic nonvoice gnosis, difficulties in evaluating and reproducing rhythms, delayed reproduction disorder, increased inhibition of traces, audio-verbal memory constriction, defective order of reproducing words (figures) in a stimulus sequence (transient errors), visual memory constriction and spatial errors in visual-constructive thinking. Such symptoms as disturbed audio-verbal and visual memory, spatial analysis and information synthesis remain almost unchanged. These symptoms belong to the sphere of functional interests of temporal and parietal-temporaloccipital cerebral regions.

Thus, positive dynamics of symptoms' manifestation was largely revealed in syndromes associated with pre- and postfrontal, parietooccipital and deep cerebral regions. At the same time the intensity of symptoms associated with temporal and parietal-temporal-occipital cerebral regions remains almost unchanged. It is well known that the overlap zone of temporal, parietal and occipital regions belongs to the tertiary cerebral cortical areas of posterior regions. These areas are multifunctional, have complex integrative functions, are the last to complete their development in ontogenesis and thus are the most susceptible to the impact of various pathological factors, which is why it is very difficult to recover them in case of a pathology. The researchers also note that epilepsy with temporal focal localization has the least favorable prognosis in terms of cognitive functions and personality alterations [26]. Examination in dynamics revealed a possibility of improving cognitive activity in children with partial epilepsy forms. The main regularity there is the considerable reduction in the manifestation of symptoms associated with extrafocal cerebral zones, while positive dynamics 
of the manifestation of symptoms associated with the epileptic focus remains insignificant; however, it should be noted that the condition does not aggravate. Positive dynamics in both focal and extrafocal disorders is likely to be more significant in case of additional purposeful recovery of the disturbed cognitive functions using nootropic drug therapy and specialized correctional exercises.

\section{CONCLUSION}

According to the neuropsychological study, complex neuropsychological symptom complexes indicating pathological functioning of various cerebral regions (specific meta-syndromes) are registered at partial temporal, occipital and parietooccipital epilepsy; the most manifested are the epileptic focal zone's symptoms, while extrafocal symptoms are less intense. In case of specific meta-syndrome, the configuration of cerebral structures, which are the most actively involved in the pathological activity, is in the first place determined by their proximity to the affection focus, usually, within the same cerebral block. It has been revealed that cerebral functions of the other cerebral blocks are less functionally deficient. The cerebral functions that are directly connected with the pathological focus appear to be the most deficient.

Dynamics of alterations in the presentation of HMF disorders, associated with the II functional cerebral block, is insignificant during remission at partial temporal, parietooccipital and occipital epilepsy forms. At the same time, neuropsychological symptoms associated with the work of the I and III cerebral blocks' structures, have significant positive dynamics 1 year later - by 87.5 and $37.5 \%$, respectively.

Epileptic cerebral processes induce cognitive activity disorders outside of epileptic foci on their own, regardless of the intensity of concurrent or initial structural defect. Disturbed HMF of extrafocal localization considerably recover even without specialized treatment in case of clinical remission at temporal, parietooccipital and occipital epilepsy forms.

Knowledge of these regularities will help neurologists and neuropsychologists to establish a more accurate short-term prognosis of mental development of children with partial epilepsy forms on the basis of the initial neuropsychological examination in case remission has been reached. Moreover, the study data should help the development of adequate psychological correction methods for cognitive disorders in children in particular cases given strong and weak links of different psychic functional systems in the setting of partial epilepsy forms. The possibility of reversibility of the mentioned symptom complexes at epilepsy remissions indicates reasonability and need in active specialized therapeutic measures (drug and psychological correctional measures) for recovering disturbed HMF in this group of children. 


\section{REFERENCES}

1. Epileptologiya detskogo vozrasta. Pod red. A.S. Petrukhina [Pediatric Epileptology. Edited by A.S. Petrukhin]. Moscow, Meditsina, 2000. 618 p.

2. Baranov A.A., Maslova O.I., Namazova-Baranova L.S. Ontogenesis of neurocognitive development of children and adolescents. Vestn. Ros. akad. med. nauk - Annals of the Russian Academy of Medical Sciences. 2012; 8: 26-33.

3. Maslova O.I., Baranov A.A., Namazova-Baranova L.S., Karkashadze G.A. Mamed'yarov A.M., Lazarev M.L. et al. Modern aspects of studying cognitive sphere in the development of children. Pediatr. farmakol. - Pediatric pharmacology. 2012; 9 (6): 72-78.

4. Karkashadze G.A. Social aspects of childhood epilepsy. Med. vestn. Sever. Kavkaza Medical bulletin of the North Caucasus. 2010; 19 (3): 30-31.

5. Karkashadze G.A., Maslova O.I., Namazova-Baranova L.S. Urgent issues of diagnostics and treatment of mild cognitive disorders in children. Pediatr. farmakol. - Pediatric pharmacology. 2011; 8 (5): 37-41.

6. Karpova V.I., Krushinskaya N.S., Mukhin K.Yu. Epilepsiya. Istoriya. Diagnostika. Praktika. Lechenie. Sovety patsientam [Epilepsy. History. Diagnostics. Practice. Treatment. Recommendations to Patients]. Moscow, Sistemnye resheniya, 2011. 224 p.

7. Prusakov V.F., Utkuzova M.A., Belousova M.V., Sivkova S.N. Epilepsy in children: course, prognosis and rehabilitation issues. Prakt. med. - Practical medicine. 2009; 38: 2730 .

8. Mikhailov V.A. Kachestvo zhizni, stigmatizatsiya i vosstanovitel'naya terapiya bol'nykh epilepsiei. Avtoref. dis. ... dokt. med. nauk [Quality of Life, Stigmatization and Medical Rehabilitation of Patients with Epilepsy. Author's abstract]. St. Petersburg, 2008. 49 p. 9. Zenkov L.R., Prityko A.G. Farmakorezistentnye epilepsii [Intractable Epilepsies]. Moscow, Medpress-inform, 2003. 196 p.

10. Balkanskaya S.V. Cognitive functions at epilepsy in children: clinical-laboratoryinstrumental parallels. Al'm. klin. med. - Almanac of clinical medicine 2005; 8 (3): 52-59. 11. Yarmukhametova M.R. Epilepsy course and prognosis. Nevrol. vestn. (zh. im. V.M. Bekhtereva) - Bulletin of Neurology (Bekhterev journal). 2012; 44 (3): 64-68.

12. Gogberashvili T.Yu., Mikadze Yu.V. Disturbed higher mental functions in children with partial epilepsy forms. Vestn. Mosk. un-ta. Ser. 14. Psikhol. - Bulletin of the Moscow University. Series 14. Psychology. 2008; 3: 80-90.

13. Mikadze Yu.V. Neiropsikhologiya detskogo vozrasta [Neuropsychology of Childhood]. St. Petersburg, Piter, 2008. 260 p.

14. Mikadze Yu.V., Gogberashvili T.Yu. Syndromes of disturbed higher mental functions in children with partial (focal) epilepsy forms. Nevrol., neiropsikhiatr., psikhosomat. Neurology, neuropsychiatry, psychosomatics. 2010; 1: 47-52.

15. Rogacheva T.A. Zakonomernosti stanovleniya i techeniya remissii pri epilepsii. Avtoref. dis. ... dokt. med. nauk [Regularities of Remission Establishment and Course at Epilepsy. Author's abstract]. Moscow, 2006.

16. Hermann B. Growing up with epilepsy: a two-year investigation of cognitive development in children with new onset epilepsy. Epilepsia. 2008; 49 (11): 1847-1858.

17. Griffith H., Martin C. et al. Cognitive functioning over 3 years in community dwelling older adults with chronic partial epilepsy. Epilepsy Research. 2007; 74 (2, 3): 91-96.

18. Baker G.A., Taylor J., Aldenkamp A.P. Newly diagnosed epilepsy: cognitive outcome after 12 months. Epilepsia. June 2011; 52 (6) 1084-1091.

19. Voronkova K.V. Evolyutsiya epilepsii i transformatsiya epilepticheskikh pristupov. Avtoref. dis. ... dokt. med. nauk [Evolution of Epilepsy and Transformation of Epileptic Seizures. Author's abstract]. Moscow, 2007, 297 p. 
20. Gogberashvili T.Yu., Karkashadze G.A., Namazova-Baranova L.S., Maslova O.I. Neuropsychological methods in pediatrics: possibilities and prospects of use. Pediatr. farmakol. - Pediatric pharmacology. 2011; 8 (6): 83-87.

21. Tsvetkova L.S. Metodika neiropsikhologicheskoi diagnostiki detei [Methods of Neuropsychological Diagnostics in Children]. Moscow, Rospedagentstvo, 1997. 127 p. 22. Sidorenko E.V. Metody matematicheskoi obrabotki v psikhologii [Mathematical Treatment Approaches in Psychology]. St. Petersburg, Rech', 2001. 308 p.

23. Wasserman L.I. et al. Metody neiropsikhologicheskoi diagnostiki [Methods of Neuropsychological Diagnostics]. St. Petersburg, Stroilespechat',1997. 400 p.

24. Trabert K. Spread of ictal activity in focal epilepsy. Epilepsia. 2008; 49 (9): 1594-1601. 25. Vingerhoets G. Cognitive effects of seizures. Seizur. 2006; 15: 221-226.

26. Isaev D.N. Psikhopatologiya detskogo vozrasta. Uchebnik dlya vuzov [Psychopathology of Children. University Textbook]. St. Petersburg, Spetzlit, 2001. 463 p. 